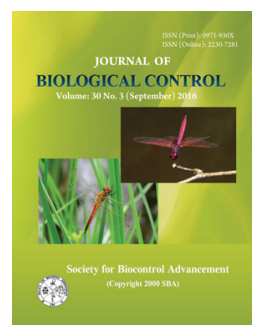

\title{
Reoccurrence of Pareuchaetes pseudoinsulata Rego Barros (Arctiidae: Lepidoptera) population in Thiruvananthapuram district of Kerala, India: A biological control agent of the weed, Chromolaena odorata (Asteraceae)
}

\author{
C. P. ARJUN, V. SAROJKUMAR, N. P. SOORAJ ${ }^{*}$, V. R. PRAKASH ${ }^{2}$, R. JAISANKAR and AMMINI JOSEPH ${ }^{1}$ \\ School of Ecological Informatics, Indian Institute of Information Technology and Management, Techno park campus, Trivandrum, \\ Kerala, India \\ ${ }^{1}$ School of Environmental Studies, Cochin University of Science and Technology, Kalamassery, Cochin-22, Kerala, India \\ ${ }^{2}$ Faculty of Veterinary and Agricultural Sciences. The University of Melbourne, Parkville, Victoria 3010, Australia \\ ${ }^{*}$ Corresponding author Email: sooraj.np@iiitmk.ac.in
}

\begin{abstract}
Authors report the reoccurrence of Pareuchaetes pseudoinsulata Rego Barros larvae at Technopark campus, Thiruvananthapuram. The larvae of P. pseudoinsulata were found feeding voraciously on terminal and axillary buds and leaves of Chromolena odorata. The recent report helps to identify the elite and resistant population for further field release to control C. odorata.
\end{abstract}

KEY WORDS: Invasive species, Siam weed, Biological control, Pareuchaetes pseudoinsulata

(Article chronicle: Received: 02-09-2016; Revised: 24-09-2016; Accepted: 25-09-2016)

Chromolaena odorata (L.) King \& H.E. Robins (Syn: Eupatorium odorata), is one of the widely distributed invasive plants in India. It causes devastating impacts on native plants by out-competing for habitat, food and other resources (Heywood, 1989). Since the physical as well as chemical eradication of $C$. odorata was found uneconomical, biological control method was identified as an effective remedy (Muniappan et al., 1988). Pareuchaetes pseudoinsulata Rego Barros was the first insect to be reported as potential biological control agent of $C$. odorata (Bennett and Rao, 1968; Cruttwell, 1968). The insect species was introduced to India from Trinidad by the Indian station of Common Wealth Institute of Biological Control in 1973. But the larval establishment of $P$. pseudoinsulata was unsuccessful due to predation by two ant species viz, Myrmicaria brunnea and Oecophylla smaragdina (Cock and Holloway, 1981). In 1984, a larval culture of the Srilankan strain of $P$. pseudoinsulata was released at Thrissur, Kerala. This attempt was successful for the field establishment of larval population. Subsequent release of $P$. pseudoinsula$t a$ in Tamil Nadu and Karnataka in 1988 were successful initially but slowly became ineffective. Another attempt in Tamil Nadu (Ahmad, 1991) was also found futile in regaining the insect population (Kumar, 2015). It was observed that parasitism on P. pseudoinsulata caused the decline of its population (McFadyen, 1997). A few reappearances of this species were reported in Tamil Nadu and Kerala (Singh and Singh, 2013). Information pertaining to the distribution and infestation of $P$. pseudoinsulata on $C$. odorata is very important in terms of its economic impact. The authors report the reoccurrence of $P$. pseudoinsulata observed during a recent vegetation survey conducted at Technopark campus $\left(8^{\circ} 33^{\prime} 26.38^{\prime \prime} \mathrm{N}, 76^{\circ} 52^{\prime} 46.23^{\prime \prime} \mathrm{E}\right)$ Trivandrum, Kerala in during the months of September-June 2015-16. The larvae of $P$. pseudoinsulata were found feeding voraciously on terminal and axillary buds and leaves of $C$. odorata Larvae of P. pseudoinsulata (24 $\mathrm{mm}$ size) are hairy and black color with interrupted thin white stripes on lateral sides of ventral and dorsal parts. Four pairs of red tubercles in 3, 5 to 9 and 11 segments were present. In contrast to previous reports of nocturnal feeding habits of $P$. pseudoinsulata (Cruttwell, 1972), daytime feeding was observed at the study sites. Averages of 18.4 larvae, 4-5 live pupae, 3 pupal cases per plant were recorded. A few larvae were collected and reared in laboratory. After two days larvae were transformed to pupae with a dark brown coloration. It remained nearly 4 weeks as pupae. Pale yellow colored P. pseudoinsulata moth) emerged out from the pupae, it was reported that the P. pseudoinsulata completes its life cycle in 39-54 days in Indian condition (Muniappan et al., 1988). After emergence, the moth laid a few infertile eggs. They were released back to the same patches. The population status 
was found abundant during rainy months (June - July and October-November) of the year. The larvae were observed feeding solitarily during the summer months in the study sites. We believe that larvae of $P$. pseudoinsulata might have generated potential resistance to predation, parasitism and adaptation to the environmental conditions prevailing in the habitats. Considering the recent recovery, nationwide survey should be conducted to study its distribution. This may help to identify the elite and resistant population for further field release to control C. odorata.

\section{ACKNOWLEDGEMENT}

Authors are grateful to Prof. M. S. Rajasree, Director of IIITM-K for continuous encouragement and support towards successful completion of the study.

\section{REFERENCES}

Ahmad M. 1991. Attempts on biological control of Chromolaena odorata in India. My forest 27: 179-186.

Bennett FD, Rao VP. 1968. Distribution of an introduced weed Eupatorium odaratum Linn. (Compositae) in Asia and Africa and possibilities of its biological control. PANS. 4: 277-281.

Cock MJW, Holloway JD. 1981. The history of, and prospects for, the biological control of Chromolaena odorata (Compositae) by Pareuchaetes pseudoinsulata Rego Barros and allies (Lepidoptera: Arctiidae). Bull Entomol Res. 72 : 193-205.

Cruttwell RE. 1968. Preliminary survey of potential biological control agents of Eupatorium odoratum in Trinidad. Proceedings of the 9th British Weed Control Conference. 836-841.
Cruttwell RE. 1972. The insects of Eupitorium odoratum L. in Trinidad and their potential as agents for biological control. Ph.D. Thesis, University of West Indies, St. Augustin, Trinidad.

Heywood VH. 1989. Patterns, extents and modes of invasions by terrestrial plants. pp 31-60. In: Drake JA, Mooney HA, di Castri F, Gorves RH, Kruger RH, Kruger RH, Kruger FJ, Rejmane, M, Williamson M. (Eds.). Biological invasions: A global perspective John Wiley, Chichester, UK.

Kumar S. 2015. History, progress and prospects of classical biological control in India. Ind J Weed Sci. 47: 306-320.

McFadyen RE. 1997. Parasitoids of the Arctiidae moth Pareuchaetes pseudoinsulata (Lep.: Arctiidae), an introduced biocontrol agent against the weed Chromolena odorata (Asteraceae), in Asia and Africa. Entomophaga 42: 467-470.

Muniappan R, Sundaramurthy VT, Viraktamath CA. 1988. Distribution of Chromolaena odorata (Asteraceae) and bionomics and consumption and utilization of food by Parauchaetes pseudoinsulata (Lepidoptera: Arctiidae) in India. Proc 7th Intl Symp Biol Control Weeds, Rome, Italy.

Singh N, Singh J. 2013. New records of a genus and four species of family Arctiidae (Insecta: Lepidoptera) from India. Rec Zool Surv India 113: 137-140. 